\section{Asymptomatic duodenal perforation from obstructed and migrated biliary stent}



Fig. 1 T-tube tract cholangiography revealed the distal end of the biliary stent located $10 \mathrm{~mm}$ into the duodenal lumen.

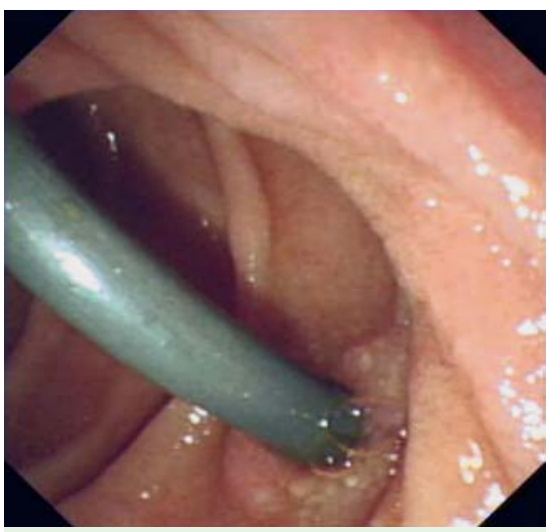

Fig. 2 The distal part of the stent was found to protrude through the contralateral bowel wall of the duodenal papilla.

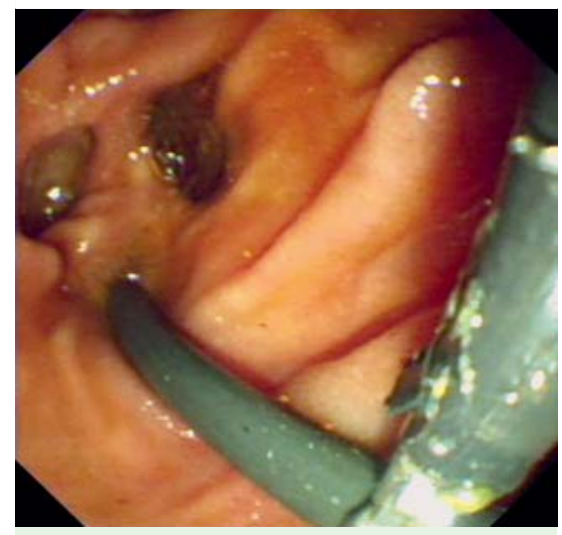

Fig. 3 The stent was retrieved using a rat tooth grasping forceps.

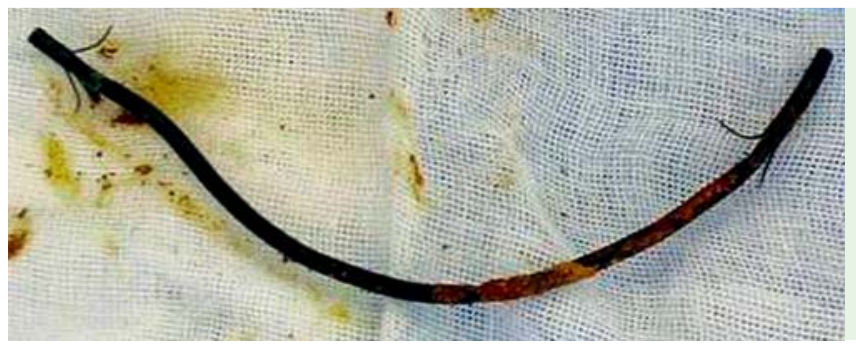

Fig. 4 The plastic stent was found to be obstructed.

Endoscopic biliary stenting has become a principal management option in the treatment of pancreaticobiliary disease. Longterm complications include occlusion, migration, and dislocation [1-3]. Duodenal perforations caused during stent migration are rare but life-threatening [4], with complications including peritonitis, sepsis, retroperitoneal abscess, and duodenal fistulization [4-5]. This report describes an asymptomatic case of duodenal perforation caused by distal stent migra-

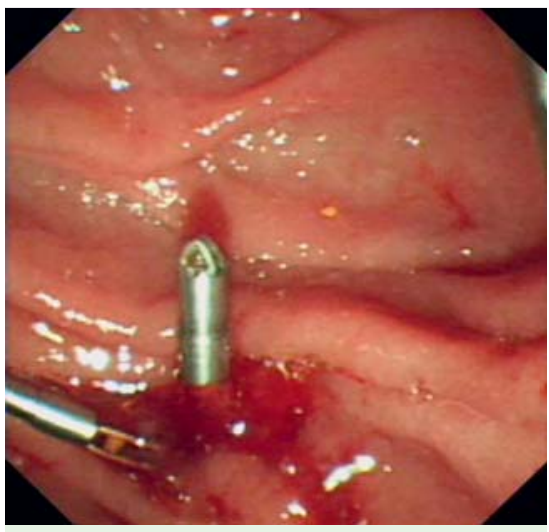

Fig. 5 The perforation wound was clamped with a hemostatic clip.



Fig. 6 Cholangiography disclosed severe filling defects in the common bile duct.

formed, and a T-tube was placed in the common bile duct (CBD). The patient made a good recovery. Twenty days later, T-tube tract cholangiography and computed tomography (CT) scan revealed the distal end of the biliary stent located $10 \mathrm{~mm}$ into the duodenal lumen ( $\bullet$ Fig. 1).

This patient presented without any symptoms of stent perforation or gallstones during a 2-year period. More recently, he was admitted to our department to determine whether or not the stent had migrated.

Under endoscopy, the distal part of the stent was found to penetrate the contralateral bowel wall of the duodenal papilla (๑ Fig. 2).

The proximal stent was in the CBD. The stent was retrieved using a rat tooth grasping forceps and found to be obstructed. The perforation wound was clamped with a hemostatic clip ( $\bullet$ Figs. 3-5).

Cholangiography disclosed severe filling defects in the CBD ( $\bullet$ Fig. 6 ).

The stones were retrieved with a wireguided basket.

In this case, the stent was obstructed before migration, so the bile could not evac- 
uate to the abdominal cavity. This might explain why the patient was without symptoms after stent migration resulted in perforation. This novel consequence suggests that regular follow-up and CT scans are needed for asymptomatic patients with biliary stenting.

Endoscopy_UCTN_Code_CPL_1AK_2AD

Competing interests: None

\section{H. Lin, Z. S. Li, X. B. Zhan}

Department of Gastroenterology, Changhai Hospital, Second Military Medical University, Shanghai, China

\section{References}

1 Libby ED, Leung JW. Prevention of biliary stent clogging: a clinical review. Am J Gastroenterol 1996; 91: 1301 - 1308

2 Arhan M, Odemiş B, Parlak E et al. Migration of biliary plastic stents: experience of a tertiary center. Surg Endosc 2009; 23: 769 775

3 Storkson RH, Edwin B, Reiertsen $O$ et al. Gut perforation caused by biliary endoprosthesis. Endoscopy 2000; 32: 87-89

4 Saranga BR, Rao P, Ghosh K. Iatrogenic duodenal perforations caused by endoscopic biliary stenting and stent migration: an update. Endoscopy 2006; 38: 1271-1274

5 Basile A, Macri A, Lamberto S et al. Duodenoscrotal fistula secondary to retroperitoneal migration of an endoscopically placed plastic biliary stent. Gastrointest Endosc 2003; 57: $136-138$
Bibliography

DOI $10.1055 / \mathrm{s}-0029-1215373$

Endoscopy 2011; 43: E40 - E41

(c) Georg Thieme Verlag KG Stuttgart · New York . ISSN 0013-726X

\section{Corresponding author}

\section{Z. S. Li, MD}

Department of Gastroenterology Changhai Hospital

Second Military Medical University

Shanghai 200433

China

Fax: +86-21-81873824

zhsli@81890.net 